\title{
EXPERIÊNCIA FEMININA E RELAÇÕES DE PODER NOS ROMANS DO SÉCULO XII
}

\section{Feminine experience and power relations in the romans of 12th century}

\author{
Prof. Dra. Carolina Gual da Silva \\ Pós-Doutoranda em História (Unicamp) -Universidade de Campinas \\ Bolsista Fapesp, processo no. 2017/20683-6 \\ ORCID: https://orcid.org/0000-0001-6534-0389 \\ carolgual@gmail.com
}

Recebido em: 25/09/2019

Aprovado em: 10/04/2020

\begin{abstract}
Resumo :
O presente artigo pretende demonstrar como a literatura pode ser uma fonte rica para uma compreensão mais ampla das diferentes maneiras em que as relações de poder se manifestam entre homens e mulheres na Idade Média. Partindo de uma análise de obras historiográficas dos anos 1980-2000, influenciadas pelos novos rumos dos estudos de gênero e pelos movimentos feministas, analisamos a maneira como o poder foi interpretado pela historiografia no que diz respeito à chamada "história das mulheres". Em seguida, para propor uma visão mais ampla do que significam as relações de poder, são analisados os romans de Chrétien de Troyes e de Béroul para demonstrar o potencial histórico dessas fontes e a complexidade das experiências femininas no século XII.

Palavras-chave: mulheres; romans; século XII

Abstract :

This paper aims to show that literature can be an important source for a broader understanding of the different ways in which power relations manifested between women and men in the Middle Ages. From an analysis of historiographical work from the 1980's-2000's, influenced by the new paths in gender studies and feminist movements, we analyze how power was interpreted by historiography in what is know as "women's history". After this, in order to propose a broader view of what power relations mean, we discuss the romans od Chrétien de Troyes and Béroul to demonstrate the historical potential of these sources and the complexity of women's experiences in the $12^{\text {th }}$ century.
\end{abstract}

Key words: women; romans; $12^{\text {th }}$ century 
Nos últimos 30 anos, a produção historiográfica sobre a mulher e as questões de gênero cresceram enormemente. $\mathrm{O}$ impulso veio de dois movimentos diferentes e interligados: o primeiro movimento dizia respeito a novas tendências teóricas no estudo da história como, por exemplo, a história das mentalidades, a história social, a nova história, entre outras. O segundo foi o movimento feminista da década de 60. Nesse caso, o interesse em estudar o papel da mulher na história estava intimamente ligado à ideia de se fazer a história dos "excluídos" como escravos, servos, trabalhadores, homens comuns e, também, as mulheres.

A historiografia medieval também foi fortemente influenciada por essas tendências. Em relação ao estudo das mulheres na Idade Média, surgiram vários estudos que avançaram significativamente nosso conhecimento sobre a condição social da mulher e sobre o seu papel na sociedade medieval. Entre os representantes deste movimento podemos destacar Eileen Power, uma das pioneiras no estudo, com sua obra Medieval Women (POWER: 1975) e também Régine Pernoud que, além de elaborar biografias de algumas mulheres célebres como Eleonor da Aquitânia e Joana D'Arc, também fez estudos mais gerais como La Femme au Temps des Cathédrales (PERNOUD: 1990) e La Femme au Temps de la Croisade (PERNOUD: 1990).

As últimas três décadas assistiram a uma explosão de obras dedicadas a revelar e destacar o lugar da mulher na história. Os mais diferentes aspectos foram abordados, desde as relações familiares até a vida religiosa, política e doméstica das mulheres. Estes estudos lançaram luz sobre áreas até então pouco conhecidas ou mal-entendidas da experiência feminina.

O movimento feminista teve uma influência fundamental em diversos trabalhos, principalmente durante as décadas de 60 e 70 . Em um momento em que as mulheres lutavam pelo seu reconhecimento em um mundo majoritariamente masculino, exigindo direitos e liberdades iguais, reconhecer a mulher como um sujeito histórico ganhava uma importância significativa. A historiografia refletiu esses ideais feministas. Duas questões ocuparam a agenda de pesquisa: desmistificar a ideia de que as mulheres estivessem excluídas da vida pública, do poder e da história no período medieval; e denunciar a condição de opressão e submissão a que as mulheres estavam sujeitas, tanto na forma de domínio patriarcal quanto por imposições políticas e sociais. Essas duas tendências devem ser entendidas mantendo-se em mente os posicionamentos políticos 
dos autores dentro de um movimento que lutava pela conquista de espaço e reconhecimento das mulheres.

Mencionei que esses trabalhos foram pioneiros, que introduziram um novo campo na pesquisa histórica. No entanto, há também, críticas que podem ser feitas. Um problema inicial que se pode destacar em algumas obras é a ênfase, e muitas vezes a limitação, às representações e imagens femininas. Alguns autores, como Georges Duby e R. Howard Bloch, não procuravam reconstruir as práticas sociais e preocupavam-se apenas com a imagem criada, por homens, das mulheres. Isto fica bastante evidente na fala de Duby na introdução de seu livro Women of the Twelfth Century: Eleanor of Aquitane and Six Others: "O que importa é a imagem que eles $<$ os textos> oferecem das mulheres (...), a imagem que o autor do texto criou e quis passar para seu público.” (DUBY: 1997, p. 2). Ao leitor, entretanto, restava uma grande dúvida: seria possível transferir essas imagens e representações para as vidas cotidianas das mulheres? Essa reflexão foi feita também por autores como Gianna Pomata que, ao escrever sobre a coletânea História das Mulheres diz: "Somos levados a nos perguntar se esta avalanche de discursos sobre as mulheres tem algum tipo de consequência prática sobre suas vidas e nenhuma dessas obras responde claramente a essa questão.” (POMATA : 1992, p. 27).

Tendo em vista o contexto que favoreceu o surgimento e crescimento de obras dedicadas às mulheres na Idade Média, uma boa parte da historiografia dedicou-se a entender melhor a relação das mulheres com o poder e este seria exatamente o segundo ponto a ser criticado nas obras. Havia um esforço contínuo em demonstrar a presença do poder, frequentemente, do poder político das mulheres.

O problema, entretanto, não está na abordagem, mas na concepção, bastante estreita, sobre o que é poder. Com frequência, poder era visto como poder político no sentido mais estrito da palavra: participação direta no governo, exercício de cargos públicos de chefia, domínio de territórios e de pessoas. Para a maioria dos autores, era quase análogo ao governo, seja este governo um governo pessoal ou institucional. Esta concepção pode ser considerada estreita pois só enxerga influência onde há cargos e títulos. As demais esferas do poder não são consideradas. Práticas cotidianas, religiosas, domésticas, amorosas não são vistas como práticas de poder e, como veremos mais adiante na análise documental, elas têm sim um caráter político que deve ser considerado. 
A partir dessas constatações iniciais, o presente artigo é composto por duas partes. Num primeiro momento, analiso como a historiografia que se desenvolveu principalmente entre os anos 1980 e 2000, à luz dos avanços da história das mulheres e dos estudos de gênero, propôs interpretações sobre a relação das mulheres com o poder na Idade Média. Na segunda parte, proponho uma leitura a partir de obras literárias nesse caso os chamados romans do século XII - para demonstrar como elas podem nos oferecer alternativas para pensarmos o poder de forma mais ampla.

\section{A historiografia medieval sobre as mulheres entre os anos 1980-2000}

Há vários exemplos, nas mais diferentes linhas de análise, que ilustram esse tipo de abordagem. Poderíamos dividi-los basicamente em dois grandes grupos de acordo com a escala da análise: o primeiro grupo seria composto por obras dedicadas a uma escala mais ampla, que englobam grandes espaços, enquanto que no segundo grupo teríamos trabalhos de cunho mais regional, ou seja, limitados a regiões menores e mais específicas. Com frequência, quanto maior a área estudada, mais estrita fica a visão de poder, e vice-versa, como pretendo ilustrar com os exemplos a seguir.

Quando menciono uma grande área de pesquisa, isto pode significar desde o que consideraríamos hoje a região de um país inteiro - a França, por exemplo - até vários "países" juntos. No caso de Georges Duby e R. Howard Bloch, os historiadores analisam uma região ampla que englobaria o que é hoje o norte, no caso de Duby, e o sul da França, no caso de Howard Bloch. Shulamith Shahar trabalha em uma escala ainda maior ao englobar em seus estudos as cidades italianas e algumas regiões das atuais Espanha e Alemanha. Em artigo escrito a quatro mãos, JoAnn McNamara e Suzanne Wemple também abrem seu campo de análise imensamente ao não explicitarem a qual região referem-se em suas conclusões levando-nos a crer, inclusive, que estas poderiam ser aplicadas a qualquer parte do continente europeu durante a Idade Média.

No segundo grupo, dedicado a estudos mais regionais, encontramos os artigos de Kimberly LoPrete, Amy Livingstone e Theodore Evergates na coletânea Aristocratic Women in Medieval France (EVERGATES: 1999). O primeiro ensaio, escrito por 
LoPrete, Adela of Blois: Familial Alliances and Female Lordship tem um caráter biográfico, o que restringe bastante o espaço de análise ao concentrar-se em torno de uma única personagem, no caso, Adela de Blois. No caso de Livingstone e Evergates, o mesmo é verdade pois a primeira delimita seu espaço à região do Chartrain e o segundo a de Champanhe. Vemos, portanto, uma diferença bastante clara entre os dois grupos: enquanto que no primeiro temos hipóteses e conclusões mais generalizadoras, no segundo as conclusões assumem um caráter mais específico.

Há ainda um caso singular que não se encaixa bem em nenhum destes dois grupos. É o caso de Régine Pernoud e sua obra La femme au temps des Cathédrales. Pernoud desenvolve uma análise que é ao mesmo tempo ampla e regional. Embora ela expanda sua pesquisa para diversas regiões, existe sempre um trabalho cuidadoso de separá-las e diferenciá-las chegando a decisões diferentes para cada região.

As diferenças podem ficar mais evidentes com uma explicitação das teses principais de cada um destes autores. Dentro do primeiro grupo, começamos por Georges Duby, historiador francês de renome, com forte tradição acadêmica, grande número de obras de qualidade sobre a Idade Média, um trabalho documental sério e que, exatamente por isso, recebeu enorme atenção da academia quando passou a escrever obras dedicadas à "história das mulheres". Entre suas mais importantes contribuições, está sua teoria sobre as transformações familiares que ocorreram na França durante os séculos XI-XII.

Esta teoria está fortemente baseada em noções de poder político. De acordo com Duby, ao longo do século XI houve uma mudança significativa nas estruturas familiares que passaram de uma organização cognática para agnática. Isto significa dizer que os laços hereditários, a herança, que inicialmente eram determinados tanto pelo lado materno quanto pelo paterno (cognática), passaram a ser estritamente patrilineares (agnática), de acordo com o autor. Como consequência, as mulheres foram excluídas do direito à herança, agora restritos ao primogênito. Além disso, elas agora não podiam contar com sua família para protegê-las. O resultado disto tudo teria sido a progressiva alienação das mulheres das propriedades e bens familiares e isto, segundo Duby, significaria menos poder para interferir política e socialmente. ${ }^{2}$

Esta tese teve grande impacto na historiografia pois passava a ser uma explicação plausível para o que se acreditava ser a ausência das mulheres da política, i.e. do poder. 
Iniciou-se assim, toda uma tradição voltada a demonstrar ou denunciar a condição subalterna das mulheres a partir da pesquisa empírica de Duby que parecia confirmar a tese.

R. Howard Bloch, também trabalhando na grande escala, segue na mesma linha quando desenvolve suas ideias sobre a predominância da misoginia na sociedade medieval, mesmo em locais onde ela aparentemente não existia. Em seu livro Medieval Misoginy and the Invention of Western Romantic Love, Bloch baseia-se na literatura cortês argumentando que esta, embora aparente ilustrar uma maneira mais positiva de retratar a mulher ao colocá-la em um pedestal, na realidade apenas indica um novo tipo de antifeminismo onde o objetivo final é a alienação da mulher da história e o seu desaparecimento enquanto sujeito: (...) antifeminismo e cortesia encontram-se em uma relação dialética (...) na qual a mulher é colocada em uma posição de superdeterminação (...) e, portanto, presa em uma trama ideológica cujo efeito final é sua abstração da história. (BLOCH: 1991, p. 164)

A maneira como Bloch busca comprovar esta ideia é exatamente a partir da tese de Duby. Ele também fala de uma mudança, no começo do século XI, na organização familiar: “(...) um deslocamento (...) para longe do clã horizontal - a solidariedade entre irmãos que incluía relações tanto agnáticas quanto cognáticas - a favor de um grupo de parentesco mais vertical (...)." (BLOCH: 1991, p. 191). Ele ressalta a diferença entre os tipos de bens que homens e mulheres herdavam, sendo os primeiros basicamente constituídos de terras e propriedades que passariam de pai para filho, e os segundos compostos primordialmente de bens móveis como roupas, louças e principalmente dinheiro, muitas vezes na forma de dote.

Portanto, para Bloch, a mulher foi excluída do domínio da propriedade e, consequentemente, do poder, uma conclusão quase análoga à de Duby. Seria dentro deste contexto que o amor cortês teria ganhado uma função ideológica, como uma forma de "compensação" às mulheres pelo poder perdido. Ao exaltar uma imagem feminina na literatura da época, o efeito era a transformação da mulher em categoria e a aniquilação da identidade individual das mulheres. E é nesse sentido que ele fala da anulação da mulher enquanto sujeito histórico, excluindo qualquer possibilidade de que ela viesse a ter poder. 
Também fazem parte deste primeiro grupo JoAnn MacNamara e Suzanne Wemple em artigo para a coletânea Becoming Visible, intitulado Sanctity and Power: the dual pursuit of medieval women (MACNAMARA; WEMPLE: 1997). Como disse anteriormente, as autoras não especificam uma área de análise e parecem generalizar suas conclusões para todo o continente. Elas também acreditam que a mulher medieval detinha pouco ou nenhum poder, entretanto, para MacNamara e Wemple isto não teria sido sempre assim.

A tese das autoras vai no sentido de comprovar que uma confluência de fatores nos séculos XI e XII teria sido responsável pela progressiva perda de poder por parte das mulheres. Entre estes fatores está o desenvolvimento de instituições de poder como a Igreja e o Estado e, com isto, a centralização política, além das transformações familiares de que fala Duby. Elas afirmam que “(...) com o crescimento de uma sociedade mais estruturada, na qual igreja e estado buscavam um controle centralizado, as mulheres da baixa Idade Média viram seus direitos e seus papeis cada vez mais diminuídos e suas ambições frustradas.” (MACNAMARA; WEMPLE: 1997, p. 116).

No entanto, trabalhar na grande escala não significa, necessariamente, acreditar que as mulheres não detivessem poder. Shulamith Shahar junta evidências de diversas regiões da Europa como França, Espanha, Inglaterra, Alemanha e Itália para comprovar exatamente o contrário. Sua argumentação gira em torno da tese de que “(..) havia mulheres na Idade Média que, em total contradição com a lei, assumiam poderes de governo como jamais visto nas sociedades romanas ou germânicas no ocidente europeu e tampouco antes do século XX." (SHAHAR: 1996, p. 12). Shahar apresenta documentos onde mulheres herdam, vendem e doam terras mesmo após o século XI. Assim, a autora concentra-se em provar que as mulheres possuíam autoridade para governar territórios e pessoas mesmo após o aparecimento de códigos legais que estipulavam o fim destes poderes e direitos, ao contrário dos três autores citados anteriormente.

No segundo grupo, de trabalhos regionais, encontramos a coletânea de ensaios Aristocratic Women in Medieval France, editado por Theodore Evergates, que apresenta um trabalho cuidadoso e extensivo de pesquisa empírica com o objetivo de, através dessa pesquisa, demonstrar que a teoria de Duby nem sempre funcionava. Como dizem os próprios editores, "O processo de construção de uma base de conhecimento segura 
sobre mulheres aristocráticas que não eram da realeza na França começou lentamente, mas já está mostrando um quadro (...) significativamente diferente daquele pintado de forma tão vívida por Duby.” (LoPRETE; EVERGATES: 1999, p. 2).

Cada um dos artigos focaliza uma pequena região da França, levando em consideração as particularidades de cada uma. Os três primeiros artigos do livro, cada um à sua maneira, seguem bem essa linha. Kimberly LoPrete, em "Adela of Blois: Familial Alliances and Female Lordship" se vale da biografia de Adela de Blois para mostrar que, mesmo com a consolidação das linhagens patrilineares, a família da mulher continuou sendo um elemento forte no jogo político dos séculos XI e XII (LoPRETE: 1999).

Os dois textos seguintes, de Amy Livingstone e Theodore Evergates são bastante semelhantes em suas abordagens. Ambos utilizam como documentação primordial doações de terra, marcando a presença feminina na sociedade medieval. Livingstone, em seu estudo sobre as aristocratas da região de Chartrain reafirma a força dos laços cognáticos, refutando a tese de Duby, "Os cartulários do Chartrain não revelam de forma alguma uma mudança tão abrupta no papel das mulheres nem nas estruturas familiares. Na realidade, a evidência indica uma continuidade nas experiências da maioria das mulheres da elite, detentoras de terras, entre os séculos XI e XII." (LIVINGSTONE: 1999, p. 72).

Evergates, utilizando documentação da região de Champanhe, mostra que o poder da mulher sobre seu dote era bastante grande e que este, ao contrário do que outros historiadores dizem (Howard Bloch, por exemplo) geralmente consistia de terras que passavam de mãe para filha. Segundo Evergates, leis da Alta Corte de Champanhe determinavam que “(...) mulheres recebiam uma quantidade substancial de propriedades feudais como dote (...) e assim tornavam-se proprietárias por direito próprio de feudos e alódios.” (EVERGATES: 1999, p. 90). Também reforça as ideias das duas autoras anteriores de que as mulheres agiam em conjunto com suas famílias e não apenas com a família do marido.

Em todos estes trabalhos mencionados percebemos o papel fundamental que o poder desempenha na argumentação dos autores. Devido a este papel central atribuído 
ao poder surge uma grande lacuna nas análises. O leitor pôde descobrir que a mulher medieval não tinha poderes políticos ou, pelo contrário, era extremamente poderosa, mas ele continua a se fazer a seguinte pergunta: como viviam as mulheres? O que elas pensavam a respeito de sua situação? Como elas agiam? O que falta é a experiência feminina, que aparece muito pouco nestas obras.

Nos ensaios da coletânea Aristocratic Women percebemos o início, ainda que tímido da tentativa de se estudar a experiência feminina, principalmente no texto de Kimberly LoPrete e de Theodore Evergates, que exploram outras dimensões das atitudes femininas como por exemplo o papel importante das mulheres na escolha de laços matrimoniais que respeitassem seus próprios interesses políticos. A meu ver, a autora que menos se preocupa em demonstrar poder e faz um esforço em compreender a atuação feminina dentro das restrições impostas buscando as estratégias utilizadas pelas mulheres dentro da sociedade medieval é Régine Pernoud em seu livro La Femme au Temps des Cathédrales.

Para Pernoud o importante não é determinar a presença ou ausência de poder das mulheres, mas compreender como as mulheres agiam. A autora acredita que as mulheres medievais desenvolveram suas próprias formas de agir, diferente da dos homens, "O exercício do poder supremo não as impedia, no entanto, de permanecerem plenamente como mulheres. Elas não tinham qualquer preocupação em imitar ou copiar um modelo masculino. Em seu comportamento (...) elas permaneciam essencialmente mulheres.” (PERNOUD: 1980, p 269). Assim, a tentativa de Pernoud é de demonstrar como certas mulheres atuavam em posições de poder. Exemplos são as atitudes de Agnes de Poitou e da Condessa Matilde que se tornam grande aliadas da Igreja - e principalmente de figuras importantes dentro da Igreja como o próprio papa - durante a reforma do século XII garantindo prestígio, respeito e poder para si mesmas (PERNOUD: 1980, p. 295).

Comparando todos estes autores analisados podemos evidenciar melhor as visões de poder. Os autores do primeiro grupo, Duby, Howard Bloch, MacNamara, Wemple e Shahar, possuem as abordagens mais estreitas de poder. Para eles o que define o papel da mulher na sociedade é, basicamente, a política: domínio de terras - a grande fonte de riqueza na Idade Média - ou exercício de cargos políticos. No segundo grupo, com os trabalhos regionais, começa a haver uma expansão na ideia por trás dos mecanismos de poder, tanto que os autores passam a considerar a manipulação de alianças familiares, de 
casamentos, e mesmo a devoção religiosa como formas de poder. $\mathrm{O}$ mesmo pode ser dito do trabalho de Régine Pernoud.

Mas mesmo estas obras ainda não consideram todas as possibilidades de análise, mantendo-se ainda presas à questão do poder e desconsiderando os aspectos mais "pessoais" da atuação feminina. Por que isto acontece? Uma primeira explicação possível é a agenda ideológica e política dos autores, como já dito anteriormente. Outro fator que, a meu ver, contribui para uma visão centralizada no poder é a maneira como os autores trabalham as fontes.

Em muitos casos, as fontes ainda são tratadas como verdade absoluta. McNamara e Wemple, por exemplo, trabalham com legislações, desde o período das invasões germânicas até as leis canônicas dos séculos XII-XIII. A partir do que as leis dizem, elas tiram conclusões sobre as condições da mulher na sociedade. Ao analisar a legislação carolíngia as autoras concluem que "A posição das mulheres seculares tornava-se mais segura através da legislação que eliminava o divórcio feito unilateralmente por homens." (MACNAMARA; WEMPLE: 1997, p. 99). Em nenhum momento elas se perguntam quais as implicações dessa legislação, e se ela realmente garantiria uma maior segurança para as mulheres. Elas nem cogitam a possibilidade de a lei ser, na verdade, um reflexo do quão problemática era a situação das mulheres naquela sociedade ou das forças por trás destas leis, como o desejo da Igreja de regulamentar o casamento.

Autores que trabalham com cartulários, caso dos autores de Aristocratic Women in Medieval France, trabalham com nomes. Em outras palavras, quando aparece um nome de uma mulher em um documento eles, automaticamente assumem que a mulher estava presente. Um bom exemplo é a maneira como Amy Livingstone trabalha com as informações de doações de terra. Numa doação, por exemplo, tem-se que "uma mulher chamada Odelina, esposa de Warin, doou terr para Marmoutier em nome de seu falecido marido." (LIVINGSTONE: 1999, p. 60). A autora se utiliza desse e outros exemplos para demonstrar que as mulheres poderiam efetuar doações de terras e, portanto, teriam uma certa autonomia sobre a sua posse.

No entanto, esse documento nos diz muito pouco sobre essa mulher que doou as terras. Não sabemos as circunstâncias em que ela o fez, quais as suas motivações, se o fez de livre e espontânea vontade ou se houve pressão para que efetivasse a doação. Não 
sabemos o que aquilo significava para ela, como ela se sentiu. A autora, em nenhum momento, faz esse tipo de pergunta. $\mathrm{O}$ grande problema está no tratamento das fontes sem uma crítica adequada, partindo do princípio que os textos são transparentes.

Os textos jurídicos, legais, os tratados teológicos, as biografias fazem parte de um universo discursivo específico. Um testamento não terá nada além dos nomes das pessoas envolvidas e dos bens considerados pois essa é a sua função. Os grandes tratados teológicos obedecem a determinadas regras de retórica e, mais do que isso, também a determinações de caráter doutrinal ou ideológico, que ditam todo o modo como um texto deve ser escrito. No caso das cartas, também se deve lembrar que, na maioria das vezes, elas não eram desinteressadas. Em primeiro lugar porque uma carta era escrita sabendo-se que seria lida por várias pessoas e, portanto, era uma forma de divulgação de ideias e também obedeciam a convenções retóricas. Além disso, o bispo ou abade que escrevia elogiando uma grande senhora tinha, na maioria das vezes, interesses por trás daqueles elogios: ele esperava conseguir terras, proteção, ajuda da senhora que governava a terra.

Um exemplo disso são as cartas de Ivo de Chartres e do bispo Hildebert para Adela de Blois, onde sabemos que os elogios feitos à Adela, como por exemplo, chamála de domina e louvar sua autoridade, estavam ligados a interesses de proteção, terras e alianças políticas contra os castelões de Blois e Anjou. Adela era uma fervorosa defensora da Igreja, efetuava doações numerosas, defendia os interesses dos bispos desde que eles também a ajudassem a defender os seus interesses, como bem nos mostra o texto de Kimberly LoPrete (1999, p. 28-29).

Quando comparamos as informações que os autores conseguem desse tipo de documentação com a que extraímos de fontes literárias, a diferença parece gritante. No romance de Chrétien de Troyes, Perceval, uma personagem poderia facilmente ser comparada a Adela de Blois de Kimberly LoPrete: Brancaflor.

Brancaflor é uma senhora. Ela administra seu castelo, é responsável pelo bemestar da comunidade que a circunda. Quando suas terras são atacadas por Clamadeu, é sua função, como senhora, proteger suas terras e os habitantes. Não conseguindo fazêlo, sente-se impotente e recorre à ajuda de Perceval. A narrativa de Chrétien, no entanto, nos deixa ver toda a angústia que Brancaflor sente diante de sua situação: 
Mes s'otesse pas ne repose

Qui an sa chanbre estoit anclose.

Cil dort a eise, et cele panse

Qui n'a an li nule desfanse

D'une bataille qui l'assaut

Mout se trestorne et mout tressaut

Mout se degiete et se demainne (...)

Mes ce n'est mi por oiseuse,

Einz se panse que ele ira

A son oste et si li dirá

De son afeire partie.

Lors s'est de son lit departie

Et issue fors de sa chanbre

A tel peor que tuitli manbre

Li tranblent et li cors li sue.

Plorant est de la chanbre issue

Et vient au lit ou cil se dort,

Et plore et sospire mout fort;

(PERCEVAL, vs. 1945-1965)
Mas sua anfitriã não repousa

Fechada em seu quarto

Ele dorme tranquilo, enquanto ela pensa

Que ela não tem meio de defesa

Contra uma batalha que lhe é imposta

Muito se revira, muito se sobressalta

Muito se agita e muito se atormenta (...)

Mas não é por uma ninharia,

Ela se decide a ir

Até seu hóspede e lhe dizer

Sobre uma parte de seus problemas.

Quando ela deixa o leito

E sai de seu quarto

Um tal faz tremer todos os membros

Tem também o corpo que sua

Chorando ela sai do quarto

$E$ vai ao leito onde ele dorme

E chora e suspire muito forte;

Percebemos o quanto estava em jogo na decisão de Brancaflor. Ela precisa defender seus domínios, mas seu exército, está reduzido, não há mais alimento, as pessoas estão fracas, doentes, não há mais como resistir. Eis que chega um cavaleiro armado a quem ela pede ajuda. Ela tem medo. Medo de que Perceval a julgue mal por ter entrado em seus aposentos no meio da noite. Medo que ele não possa ajudá-la. Medo de perder suas terras. Medo de ser aprisionada por outro homem.

Dessa forma, a literatura pode fornecer novas abordagens e sugerir novos caminhos. Mais do que um simples nome ou assinatura presente em um cartulário, podemos, com a descrição de Chrétien de Troyes, ter uma dimensão dos sentimentos e das ações envolvidas e, a partir daí fazer outras leituras, como veremos mais adiante na análise documental.

No entanto, valer-se de documentos literários não significa que necessariamente vá se atingir essa dimensão da experiência feminina. Um exemplo é R. Howard Bloch, que também trabalha com a literatura como evidência histórica. Mas continua havendo um problema na abordagem das fontes. Bloch está apenas preocupado em mostrar as matrizes da misoginia e as suas faces na sociedade medieval através de textos escritos, em sua maioria, por homens. 
Em Medieval Misogyny and the Invention of Western Romantic Love, Bloch analisa os recursos utilizados pelos autores dos romances de cavalaria e da poesia lírica, sob uma ótica de repressão da mulher. Analisando apenas o aspecto das relações amorosas narradas por essa literatura, ele conclui que "(...) ao não ser reconhecida pelo que é realmente, a cortesia era uma ferramenta muito mais eficaz até mesmo do que a misoginia para a o sentimento de posse em relação à mulher (...).” (BLOCH: 1991, p. 195-196).

Nenhum dos outros aspectos, como por exemplo os contextos histórico e social que aparecem no texto são levados em consideração. A mulher não é observada em nenhuma situação fora do relacionamento amoroso. Ao fixar sua análise apenas na relação amorosa, Bloch não vê as esferas onde a mulher não está sendo anulada ou subtraída ou mesmo as outras formas que ela tem de aparecer na sociedade que não no interior da relação com o cavaleiro.

Tratados teológicos também podem trazer falsas impressões sobre como era a vida das mulheres na Idade Média. Bloch, por exemplo, escolhe, aleatoriamente, textos que são abertamente misóginos com o intuito de mostrar o quanto a misoginia era uma característica essencial da sociedade medieval. Mas isso não nos permite ver o quanto essa misoginia afetava as mulheres ou, mais importante, como elas reagiam a ela.

Efetivamente, em alguns casos, houve restrição do acesso da mulher a algumas posições, no entanto, como ela reagiu diante disso tudo? Mais uma vez, a evidência literária pode contribuir para entendermos melhor as estratégias sociais da mulher numa sociedade que procura reduzir os seus espaços de ação. As donzelas dos romances conhecem bem os valores da sociedade em que vivem e sabem bem o lugar que ocupam ou devem ocupar. A partir deste saber, manipulam situações em seu próprio proveito.

Pretendo, portanto, explorar o caminho aberto pelos romances de cavalaria em busca de maior conhecimento sobre a experiência feminina, experiência esta que, a meu ver, pouco foi considerada pela historiografia. As críticas feitas aqui a esta historiografia sobre a mulher medieval não têm a intenção de pregar um descarte de toda essa tradição. Todas as obras citadas possuem um inegável valor histórico e tiveram uma contribuição fundamental no estudo das mulheres. Entretanto, para começarmos a entender um pouco sobre como era a vida das mulheres durante a Idade Média é preciso ir além da representação, é preciso expandir nossa visão sobre poder, é preciso trabalhar 
com outros tipos de fontes e mergulhar em um universo que é mais pessoal do que institucional. Para isso devemos mudar o foco. Acredito que uma leitura de romances de cavalaria, onde o foco é deslocado do cavaleiro para a donzela, pode ocasionar esta mudança.

\section{Os romans como fonte para a uma noção mais ampla de poder}

Ao trabalhar com a literatura como fonte, alguns cuidados metodológicos são necessários. Em primeiro lugar, é preciso levar em consideração aquilo que Carlo Ginzburg chamou de potencialidade cognitiva da literatura. Para o autor, tanto a História quanto a literatura possuem elementos da realidade pois têm "implicações cognitivas" (GINZBURG: 1994, p. 388). Significa dizer que a história lida em público ou em particular age sobre as pessoas, tanto no inconsciente quanto no consciente, reforçando, criando e transformando ideias, valores, costumes, ações e hábitos. Como mostrarei mais adiante, esta dimensão está bastante presente nos romances de cavalaria: o autor dirige-se diretamente a seu público ensinando-o a agir, reforçando seus valores e criando novas normas e ideais sociais.

À percepção da potencialidade cognitiva dentro dos textos podemos somar o desvelamento do conteúdo latente na tentativa de extrair o conhecimento histórico. Inicialmente, é preciso ter em mente que todo texto possui dois tipos de referenciais, os visíveis e os invisíveis. O primeiro tipo, “(...) intencionais, nomeados, descritos, caracterizados, demonstrados (...).” (POMIAN: 1989, p. 126) representa o conteúdo manifesto do texto. Mas, segundo Pomian,

(...) nenhuma obra pode ser reduzida a seu conteúdo manifesto; este está sempre e necessariamente acompanhado de um conteúdo latente que veicula tudo o que o autor de uma obra, ao produzi-la, faz entrar nela sem que esteja consciente disso e, por consequência, não está dado logo de cara. (POMIAN : 1989, 128)

O conteúdo latente de que fala Pomian representa as referências implícitas do texto, aquilo que não está evidente na forma da trama em si. Nos romances de cavalaria, 
o conteúdo latente seria o contexto histórico-social que o autor apresenta. Se retomarmos um exemplo utilizado mais acima, da ação de Brancaflor em Perceval, isto fica mais evidente:

Ressaltei anteriormente os sentimentos de Brancaflor apresentados pelo autor: o medo, a angústia, a indecisão. Esta é uma parte importante da análise textual. No entanto, é apenas o conteúdo manifesto do texto. Um pesquisador que se limitasse a observar apenas o que é dito pelo texto, poderia chegar à conclusão de que realmente a mulher era frágil, indecisa, incapaz de agir sem a ajuda de um cavaleiro. Mas, se olharmos o conteúdo latente, pode-se chegar a outras conclusões a partir da descrição de Chrétien de Troyes.

O que chama a atenção para a figura de Brancaflor não é seu medo ou insegurança, é o fato de ela ser uma grande senhora; o contexto social e histórico descrito por Chrétien de Troyes nos leva a vê-la assim. Ela é quem domina o castelo. Tem uma função política importante: há um grupo de cavaleiros e vassalos que a servem e que também dependem dela. Quando ela se senta com Perceval, permanece no centro: "Ao redor estão postados pequenos grupos de cavaleiros silenciosos, olhos fixos nesse que, perto de sua senhora, não diz palavra.” (PERCEVAL, vs. 1855-1857). Ela controla as terras, toma as decisões, deve fornecer comida e casa a seus dependentes. Há um outro senhor que disputa sua terra. Ela precisa defendê-la, salvar seus vassalos e certificar-se que eles não a abandonarão. Tudo isso aparece apenas como um pano de fundo, é a ambientação criada pelo autor. Mas é exatamente essa ambientação que nos permite apreender melhor o universo de ações de Brancaflor. É sua função política de senhora daquelas terras que a faz pedir ajuda a Perceval - uma atitude que não está ligada, necessariamente, ao fato de ela ser mulher, uma vez que um senhor enfraquecido também poderia se ver obrigado a recorrer à ajuda de um cavaleiro.

Vemos, portanto, que o conteúdo latente dos romances de cavalaria tem uma relação direta com o contexto histórico-social uma vez que o autor está, ele próprio, inserido neste contexto. Há um engajamento com as questões da época, com as mudanças sociais, com a ambientação política, com a moral e com a psicologia do período. O trabalho do historiador, então, seria complementar a análise do conteúdo manifesto com a análise do conteúdo latente, o que possibilitaria a reconstrução de uma dimensão mais profunda da história, “A explicitação dos conteúdos latentes permite, 
assim, reconstruir o passado em suas dimensões sociais, religiosas, institucionais, intelectuais, artísticas (...).” (POMIAN : 1989, P. 129).

A explicitação do conteúdo latente também permite uma dimensão mais individual, dando vida às pessoas e não apenas às instituições. É, portanto, uma forma de recuperar os agentes históricos, sejam eles homens, mulheres, crianças, trabalhadores, reis etc. Assim, no esforço de uma compreensão mais ampla do que seriam as relações de poder entre homens e mulheres na Idade Média, tomaremos a ideia de romance histórico e a explicitação de conteúdos latentes como base para a interpretação dos romans de Chrétien de Troyes, Thomas e Béroul, compostos na segundo metade do século XII.

A riqueza das informações obtidas através da leitura dos chamados "romances de cavalaria" é imensa: há uma grande variedade de situações e de personagens. Antes de analisar as situações e interpretá-las, é necessário observar quem são as mulheres que aparecem nas histórias. Deixo claro que a maioria das personagens pertence à nobreza e, portanto, não tenho a pretensão de buscar a experiência feminina de nenhum outro grupo social que não o das nobres.

Mesmo entre estas damas da aristocracia há diferenças de status e uma leitura preliminar das obras alerta para a inexistência de um único modelo de donzela. Dependendo do momento, da condição social, do desenrolar dos acontecimentos cada mulher atua de uma forma específica na sociedade. A partir das imagens criadas pelos autores, somos apresentados a damas recatadas, esposas fiéis, promíscuas, "boas", más"; mulheres caridosas e mulheres vingativas, poderosas e enclausuradas, instáveis e equilibradas; rainhas que influenciam a vida da corte e jovens princesas que devem provar seu valor; damas inteligentes e astutas e outras profundamente ingênuas. Assim, não há um comportamento único e universal e classificar todas as mulheres em um grupo homogêneo leva a falsas generalizações.

R. Howard Bloch ressaltou em sua obra Medieval Misogyny o quanto a sociedade durante a Idade Média era misógina. Ele analisou tratados teológicos e mesmo obras literárias para comprovar a presença desta misoginia, entretanto, não analisou como este sentimento antifeminino atingia as mulheres do período. Seguindo Bloch, não podemos negar a existência de sentimentos e atitudes misóginas na sociedade medieval, uma vez que os próprios romances de cavalaria comprovam-na. A violência contra as mulheres 
aparece, aqui, como uma forma de expressão destes sentimentos de aversão e até mesmo ódio.

A violência que aparece nas histórias é de dois tipos diferentes: físicas ou psicológicas. As físicas, algumas vezes, são de uma imensa crueldade, mas podem aparecer também na forma de pequenas agressões. A violência psicológica não deixa "marcas" nos corpos, mas, a partir de insultos ou ações, humilham moralmente as mulheres.

As pequenas agressões são, na maioria das vezes, dirigidas a mulheres com status social mais baixo como acompanhantes de grandes damas, aias e servas. Na corte do rei Artur há várias donzelas que fazem companhia à rainha Guinevere. Quando Perceval chega à corte pela primeira vez e é zombado por todos os outros cavaleiros, uma destas donzelas sorri para ele e profetiza o seu futuro dizendo que ele será o melhor cavaleiro do mundo caso complete toda sua vida (PERCEVAL, vs, 1039-1043). Ora, o senescal Kai, irrita-se com a fala da donzela e lhe dá um tapa: "de la paume na la face tandre, qu'il la fist a la terre tandre" (com um grande golpe da mão no rosto delicado, que a lançou ao chão) (PERCEVAL, vs 1051-1053). Para Kai, a donzela fora ousada em demasia. Ela desafiou todos os outros cavaleiros ao defender o potencial de Perceval e não tinha posição social para isto: era apenas uma dama de companhia que precisava ser devolvida ao seu devido lugar. A donzela terá sua vingança pois Perceval realmente tornar-se-á um grande cavaleiro e enviar-lhe-á todos os prisioneiros a fim de reparar o mal causado por Kai. No entanto, a humilhação da agressão pública permanece, e a agressão física, então, junta-se à violência psicológica que deixa rastros muito mais duradouros.

De la bufe que ele ot prise Estoit ele bien respasse Mes oblïe ne passee La honte n'avoit ele mie, Que mout est mauvais qui oublie, S'na li fet honte ne leidure (PERCEVAL, vs. 2896-2903)

\author{
Do golpe que sofrera \\ Estava bem recuperada, \\ Mas não fora esquecida nem passada \\ A vergonha que sofrera \\ Pois é vil quem esquece \\ A vergonha ou injúria que recebeu.
}

A violência dirigida contra damas de status mais elevado é, frequentemente, mais dura e com forte conotação sexual. Todas as grandes damas que aparecem nos romances 
lidos, em algum momento de suas vidas, têm que lidar com algum tipo de agressão sexual. Logo no início da jornada de Perceval ele encontra uma tenda com uma donzela que dorme sozinha. Resolve que irá beijá-la, apesar da sua recusa e suas súplicas. A cena que Chrétien de Troyes constrói parece a descrição de um estupro:

Li vaslez avoit les braz forz Si l'anbrace mout nicemant Car il nel sot feire autremant: Mist la soz lui tote estandue, Et cele s'est mout desfandue Et deganchi quanqu'ele pot Mês desfanse mestier n'i ot, Que li vaslez na un randon La beisa, volsist ele ou non, Vint foiz, si com li contes dit. (PERCEVAL, vs. 700-709)
Mas o jovem tem braços fortes

E a abraça desajeitadamente

Pois ele não sabe fazer de outra forma:

Segura-a deitada sob si

Mesmo ela se defendendo muito

E debatendo-se o quanto podia

Mas seus esforços foram vãos

Pois o jovem seguidamente

Beija-a, quer ela queira ou não,

Vinte vezes como diz o conto.

Após satisfazer-se, Perceval ainda rouba o anel da donzela, bebe o vinho e come as tortas que encontra na tenda. Quando o cavaleiro, amigo da damizela, retorna, enraivece-se e a acusa de ter consentido nas ações de Perceval e impõe-lhe dura pena:

Que ne mangera d'avaine

Vostre chevaus, ne n'iert seigniez

Tant que je m'na serai vangiez;

Et la ou il desferrera,

Ja mes referrez ne sera.

S'il muert, vos me siuroiz a pié,

Ne ja mes seront changié

Li drap don vos estes vestue,

Einz me siuroiz a pié et nue

Tant que la teste na avrai prise;

(PERCEVAL, vs. 822-831)
Não comerá nunca mais aveia nem será cuidado seu cavalo

Até que eu seja vingado

Se ficar sem ferradura,

Não será mais ferrado.

Se ele morrer, você me seguirá a pé

Nunca mais você trocará

As roupas que veste

E me seguirá a pé e nua

Até eu ter cortado a cabeça dele;

Um certo tempo depois, Perceval reencontra a donzela, sobre um palafrém muito magro e cansado. Ela tem as vestimentas rasgadas, remendadas, sujas:

Et sa charz paroit dehachiee, Que ele l'ot crevee et arse De chaut, de halle et de gelee. (PERCEVAL, vs. 3725-3728)
E sua carne estava ferida

Como a golpes de lanceta

Queimada, gretada por granizo e neve. 
Se pensarmos no caráter didático dos textos em relação ao comportamento sexual da cavalaria, este trecho parece desempenhar especialmente bem essa função. Chrétien está condenando as atitudes dos dois cavaleiros, tanto de Perceval quanto do amigo da damizela. O público sabe que a donzela lutou, que foi atacada contra sua vontade, que Perceval agiu de forma inadequada e mais ainda seu amigo que a condenou quando ela não tinha culpa. $\mathrm{O}$ autor aponta exatamente para a necessidade de controlar este impulso sexual exagerado dos homens mostrando o estado deplorável em que se encontra a donzela, "Einz tant cheitive ne vit nus" (Uma tão miserável nunca fora visto) (PERCEVAL, VS. 3716), tanto física quanto mentalmente: “Deus, einsi con tu le sez bien (...) m'anvoies tu, se il te siet, (...) tu de celui me delivre qui a tel honte me fet vivre." (Deus, suplico, envia alguém que me arranque deste penar ou me liberte de quem me impõe tão grande vergonha!) (PERCEVAL, vs. 3757-3762). Neste mesmo romance há uma alusão mais explícita ao estupro. Gawain, interrogando sobre um certo cavaleiro que quer desafiá-lo, assim fala:

Est tu donc ce, Greoreas, Qui la dameisele preïs Par force et ton buen na feïs? Neporquant bien savoies tu Qu'an la terre le roi Artu Sont puceles asseürees; Li rois lor a triues donees, Si les garde et si les conuit (PERCEVAL, vs. 7118-7125)
Seria você, então, o Greoreas, Que tomou a damizela

A força e a desfrutou?

Entretanto você bem sabia Que na terra do rei Arthur As jovens são protegidas; $\mathrm{O}$ rei tomou medidas a seu favor E as protege em seus deslocamentos.

Mais uma vez observamos o tom "educativo" do autor, mostrando que o estupro é algo errado, que na corte de Artur, a corte ideal, as mulheres são protegidas, que o cavaleiro que desobedece a lei é condenado (neste caso, ele fora obrigado a se alimentar com os cães durante um mês com as mãos atadas às costas).

Em Erec e Enide também há exemplos de violência de caráter sexual, embora ela não chegue a ser concretizada. A princesa Enide, durante as provações pelas quais passa, recebe por duas vezes os galanteios de condes: o de Galoin e o de Limors. O primeiro indigna-se com a recusa de Enide em aceitar o seu amor, entretanto, nada faz contra ela pois Erec está presente para defende-la. O conde de Limors, porém, acolhe uma Enide 
que julga ser viúva pois o marido havia sido gravemente ferido em combate. Obriga a dama a sentar-se à mesa de banquete e lhe propõe casamento:

Sovoingne vos de quel poverte

Vos est grans richece aoverte:

Povre estiez, or estes riche.

N'est pas Fortune envers vos chiche

Qui tel honor vos a donee

C'or seroiz contesse clamee. (...)

Quant je espousee vos ai

Mout vos devez esleescier

Gardez vos de moi corrocier:

Maingiez, que je vos em semong,

(EREC ET ENIDE, vs. 4795-4807)
Lembre-se de qual pobreza lhe tirei

e que riqueza lhe ofereço:

Pobre era, agora é rica.

A Fortuna não é avara com você

pois lhe deu a grande honra

de ser chamada de condessa. (...)

agora que eu me casei com você

Muito deve ser seu júbilo.

Evite me deixar em cólera

Coma, pois assim eu lhe ordeno.

Enide não acata suas ordens. Recusa-se a comer ou beber. $\mathrm{O}$ conde, irritado, batelhe no rosto e a ameaça caso ela não cumpra suas ordens. Grita diante de toda sua corte: "La dame est moie et je suens, si ferai de li mon plesir!" (A dama é minha e eu sou seu, e farei dela segundo meu prazer) (EREC ET ENIDE, vs. 4832-4833). Bate-lhe novamente, enquanto a dama esbraveja jurando não se entregar. A intenção do conde fica bastante clara: ele a tomaria a força. Isto só não se concretiza pois Erec volta a si e salva a esposa.

A violência de caráter sexual não está necessariamente ligada ao estupro. No caso de Isolda, sua punição deve-se ao seu próprio comportamento sexual inadequado: o rei Marc, seu marido, condena-a pelo adultério. Quando Isolda é surpreendida com Tristão, tem suas mãos atadas com tal força que o sangue jorrava. Em seguida, ela é arrastada para o local onde uma fogueira de espinheiros está sendo preparada para queimá-la. A condenação, entretanto, é muito pior: Marc decide entregá-la a um grupo de cem leprosos para que eles a possuam. Dessa forma, ela não sofreria uma morte rápida, mas passaria o resto de seus dias pagando por sua traição, como diz Yvain, um dos leprosos:

Veez, j'ai ci conpaignons cent :

Yseut nos done, s'ert conmune.

Paior fin dame n'ot mais une.

Sire, en nos a si grant ardor

Soz ciel n'a dame qui un jor

Peüst soufrir nostre convers :

Li drap nos sont au cors aers.
Veja, eu tenho cem companheiros:

Nos dê Isolda, para o comércio do corpo.

Pior fim para uma senhora não há.

Senhor, em nós há um grande ardor

Sob o céu não há nenhuma senhora

Que aguente nosso contato:

As roupas estão coladas ao nosso corpo. 
O toi soloit estre a honor,

O vair, o gris et o baudor; (...)

Se la donez a nos, meseaus,

Qant el verra nos bas bordeaus

Et eslira l'escouellier (...)

Et l'estovra a nos couchier

Qant or verra la nostre cort,

Adonc verrez si desconfort.

Donc voudroit miex morir que vivre,

Donc savra bien Yseut la givre

Que malement avra ovré :

Mex voudroit estre arse en un ré.

(BÉROUL, vs. 1192-1216)
Contigo costumava ser honrada,

Com variedades, peles cinzas; (...)

Dê ela a nós leprosos,

Quando ela ver nossa pequena cabana

E escolher o castrador (...)

Lhe será necessário dormir conosco

Quando vier a nossa corte,

Ela então verá seu desconforto.

Então desejará mais a morte que a vida,

Saberá bem Isolda a víbora

Que maldosamente agiu:

Desejará mais ser queimada em um forno.

É uma punição de extrema crueldade que só não acontece porque Tristão salva a amada a tempo. É um tipo de alerta para as mulheres: comportem-se, sejam fiéis a seus esposos pois o preço do adultério pode ser duro demais. A educação aqui não é só para os cavaleiros e seus desmedidos apetites sexuais, é também dirigida às mulheres que devem saber se comportar como esposas.

Isolda é novamente submetida a uma provação quando é obrigada a passar pelo julgamento pelo ferro em brasa, que é uma forma de julgamento também bastante violenta mas que não está limitada às mulheres, sendo prática bastante comum do período para comprovação de culpa ou inocência (BARTLETT: 1986).

Em Cligès, a violência imposta a Fenice ilustra a desconfiança de seu marido e dos médicos quanto à sua "morte". O marido permite que os médicos fiquem a sós com Fenice. Estes, querendo comprovação da sua morte açoitam-na até tirar o sangue e em seguida ameaçam:

Lors dient que il lor estuet

Feu et plom querre, sel fondront

Em la main geter li voldront Ençois que parler ne la facent (CLIGÈS, vs. 5916)
Dizem então que é preciso

Procurar fogo e chumbo, que derreterão

Para derramar em suas mãos

Para não falharem em fazê-la falar.

Esses médicos parecem saber da ação de filtros que podem fingir uma morte. Não creem que Fenice morreu e desejam prová-lo. Ela é salva por algumas damas que lançam os homens pela janela. 
Dei vários exemplos da violência a que estavam expostas as mulheres medievais. Mas o que outras informações podemos tirar destes relatos? Em primeiro lugar, destaca o fato de as damas terem consciência do perigo que correm. A donzela que é surpreendida por Perceval, antes mesmo que ele entre em sua tenda, teme por sua segurança. Ela tenta lutar contra o ataque, porém a força prevalece. Enide, quando cortejada pelos condes tem duas reações diferentes: quando sabe que o marido poderá ajudá-la, mente para o conde, fingindo aceitar o seu amor para acalmá-lo. Em seguida denuncia o traidor ao marido que a defende. Num segundo momento, quando se vê diante do conde de Limors, crendo que seu marido está morto, tenta defender-se sozinha, grita, recusa-se a ceder.

A violência está presente. As mulheres bem o sabem. Sua defesa, na maioria das vezes é recorrer à ajuda de um cavaleiro. Quando não há um para salvá-las, tentam lutar sozinhas, no entanto, pela força física, são quase sempre vencidas. Todas elas têm medo. Isolda, quando percebe que ela e o amante foram encontrados por Marc na floresta, teme a possível reação do marido. A donzela de Perceval sabe que não é seguro estar só com um cavaleiro desconhecido, se autocondena por deixar-se encontrar sozinha, ou seja, conhece a sociedade em que vive e sabe que sua melhor proteção é estar sempre acompanhada. Assim, vemos como as mulheres aprendem a reagir às agressões que sofrem, algumas vezes manipulando os homens, como Enide, outras enfrentando seus agressores, outras buscando o auxílio de um cavaleiro, muitas vezes até fugindo, como Isolda.

Falei também de uma violência que é mais psicológica que física. Esta pode aparecer sob a forma de pequenos atos de humilhação pública ou como atitudes de repressão. Um bom exemplo do primeiro caso é quando um cavaleiro derrama, propositalmente, vinho sobre a rainha Guinevere. Não é uma agressão física, no entanto, a rainha sente-se profundamente humilhada. Ela vê sua posição de rainha, de senhora, desrespeitada por um cavaleiro de status inferior e isso fere sua honra. É uma forma de violência.

A provação pela qual passa Enide também é muito mais simbólica do que física. Erec quer que ela comprove seu valor, que demonstre ser digna da posição que recebeu a partir do seu casamento. Ela sofre com os desafios pelos quais passa mas sabe como deve agir para garantir a sua honra. 
A repressão como forma de violência psicológica é bem expressa pelos casamentos arranjados, sobre os quais falarei com maiores detalhes mais adiante. Isolda e Fenice sofrem com maridos que não foram escolhidos por elas. Encontram, cada qual a seu modo, maneiras de driblarem estas prescrições e ficarem com os homens que amam.

A meu ver, estes relatos de violência contribuem para entendermos melhor as reações femininas. Sabemos que as mulheres estavam expostas a muitos perigos. Porém, poucas vezes explorou-se como esta violência afetava as mulheres. A partir dos exemplos citados, fica claro o medo que elas sentem, o quanto o seu cotidiano é afetado e a consciência que têm do perigo. A violência modifica seus hábitos, faz com que elas procurem nunca estar sozinhas com outro homem; com que se passem por mortas para escapar de um casamento indesejado; que tenham que recorrer à ajuda de homens para sua proteção, que tenham, muitas vezes, que fugir, lutar, iludir.

Mas para além da violência contra elas, como as mulheres aparecem nesses romances? De que maneira os autores constroem uma imagem feminina, quais as características dessas mulheres, como elas agem? Há muitas mulheres presentes nos romances, tanto entre os personagens principais quanto secundários. As questões que se colocam estão relacionadas aos valores atribuídos a essas mulheres, ao que é considerado, nos textos, como um comportamento feminino e se é possível categorizar essas mulheres. Na verdade, a leitura dos romances nos aponta para uma grande diversidade, não sendo possível encontrar uma única imagem de mulher e muito menos uma categoria que corresponda à "mulher medieval".

No Romance de Tristão e Isolda, várias características podem ser percebidas, como por exemplo, o domínio de certos saberes. A mãe de Isolda, e a própria dama, conhecem os segredos das ervas e plantas na elaboração de feitiços e curas. Se em Tristão e Isolda esse saber pertence à rainha, em Cligès quem comanda os filtros e poções é Tessala. Esse conhecimento é muito positivo pois são as mulheres que curam os doentes quando ninguém mais obtém sucesso. A rainha Isolda é mostrada como sendo muito astuta e capaz de lidar com as palavras. Ela sempre consegue enganar seu marido Marc e os outros barões sem que, necessariamente, minta, por saber jogar com as palavras. Quando é assediada pelo conde Galoin, consegue iludi-lo fingindo aceitar seu amor para depois denunciá-lo a Erec. Em outras ocasiões, no entanto, ela não tem a 
mesma capacidade. É por não saber escolher bem as palavras, ou mesmo por ter falado, que ela é obrigada a passar por uma provação imposta pelo marido.

A rainha Guinevere comanda vassalos e ajuda a tomar decisões na corte, em Erec e Eneida. É para ela que Erec manda os prisioneiros, é a ela que pede permissão para deixar a corte. Eneida, no entanto, não é mostrada sob o mesmo aspecto. Ela auxilia Erec e o ajuda a se salvar de emboscadas, mas não aparece entre vassalos próprios como é o caso de Isolda.

As servas também têm um papel importante. Em Tristão e Isolda, além de ser uma serva quem dá o filtro aos dois amantes, é Brangien, serva de Isolda, quem os protege e alerta do perigo. É Tessala, serva de Fenice, quem auxilia na realização do amor entre sua ama e Cliges. É a serva de Guinevere que é enviada para descobrir quem é o misterioso cavaleiro e sua dama durante a caçada. As servas de Fenice e Isolda são também suas amigas e confidentes.

Temos algumas mulheres sendo extremamente caridosa e amadas por toda a população. É o caso de Isolda. Embora mostrando-se muito vingativa ao tentar matar Tristão para vingar a morte de seu tio, Isolda também perdoa, não apenas Tristão, mas também sua serva. Porém temos também a Isolda das Brancas Mãos cuja vingança provoca a morte de Tristão.

Um aspecto interessante é a visão que a mulher tem de si própria, como por exemplo, em relação ao casamento arranjado. Isolda, ao ser prometida para Aguynguerran, indigna-se, não pelo casamento arranjado, mas pelo fato de ele ser um covarde. Isolda se preocupa com sua honra e toma uma atitude para que esse casamento não ocorra. $\mathrm{O}$ filtro que sua mãe prepara é para garantir que ela e seu futuro esposo, o rei Marc, fiquem apaixonados e vivam felizes. É uma preocupação e uma maneira de resolver o problema do casamento arranjado. Fenice também não deseja casar com Alis. Mas seu problema é que ela está apaixonada por Cligès. Ela não ousa pronunciar-se contra a opção do pai, mas arranja um recurso para não concretizar o casamento: o filtro de Tessala. Eneida, por outro lado, é “dada" em casamento a um cavaleiro - Erec - que nunca havia visto antes e nada tem a dizer.

A mulher nos romances também passa por algumas provações. Eneida é levada em uma aventura por Erec para ser testada e provar seu amor pelo marido. Isolda é 
obrigada a fazer um juramento pelo ferro em brasa. Fenice, quando se passa por morta é açoitada, tem chumbo derretido derramado nas mãos. É salva por algumas damas que libertam-na e jogam os médicos pela janela. Nas três situações as mulheres conseguem passar pelas provas. São mulheres fortes que sobrevivem às mais dolorosas penas. A serva de Guinevere, no entanto, ao questionar o anão sobre a identidade da dama na floresta, recebe uma chicotada e foge aos prantos.

Como podemos ver, as características apresentadas das variadas mulheres são bastante diversas. Temos mulheres fiéis, promíscuas, boas e más esposas. Mulheres caridosas e mulheres vingativas. Mulheres poderosas e mulheres enclausuradas. Mulheres instáveis e equilibradas. Mulheres que participam da vida da corte e que vivem apenas entre mulheres. A rainha Guinevere tem uma grande influência na vida da corte como um todo. Eneida, porém, muito jovem, precisa passar por várias "provas" para assegurar seu valor como rainha. Temos servas com conhecimentos de cura e poções e servas que, por ignorância, servem o filtro às pessoas erradas. Mulheres que demonstram emoções e reagem a situações sociais de forma distinta. Fenice critica o comportamento de Isolda, mas também não ama seu marido. Eneida vive feliz com um marido que a ama a ponto de abandonar todas as outras coisas para permanecer ao seu lado.

Conclui-se, portanto, que não podemos pensar em uma mulher única nos romances de cavalaria. Existem características diferentes em diferentes situações. Servas e rainhas não são tratadas da mesma forma. Mesmo entre as damas da nobreza existem variações. Ressalta-se a beleza das mulheres, seu recato, suas qualidades físicas. Mas não existe um comportamento único e universal. Contrapondo-se estes textos a documentos legais, cartulários, testamentos, temos uma melhor dimensão das ações pessoais, o plano das emoções e dos sentimentos e as diferentes relações estabelecidas entre os vários sujeitos. Ao pegarmos os textos literários, podemos perceber a diversidade de atitudes e tentar descobrir o que existe por trás das ações destas mulheres.

A preocupação com a questão do poder das mulheres sempre foi central na historiografia, como vimos para o caso dos autores analisados para as duas décadas finais do século XX. No entanto, o debate em torno do poder feminino nos séculos XIXIII precisa ser constantemente ampliado para incluir as diferentes formas de ação 
relacional. Não se trata, apenas, de descobrir se a mulher detinha ou não poder, mas de entender a experiência feminina e refletir sobre a dinâmica das relações sociais das quais as mulheres faziam parte e descobrir como essas mulheres se sentiam e agiam em relação a sua condição social. A literatura, como procurei demonstrar, pode ser um caminho interessante para esse tipo de análise.

\section{Referências bibliográficas:}

\section{Fontes:}

BÉROUL. Le Roman de Tristan. Paris: Association de Bibliophiles Universels, 1999. Disponível em: http://abu.cnam.fr. Acesso em 10 de setembro de 2019.

CHRÉTIEN DE TROYES. Le Chevalier de la Charrette. Paris: Lettres Gotiques, 1992.

CHRÉTIEN DE TROYES. Le Chevalier au Lion. Paris: GF Flammarion, 1990.

CHRÉTIEN DE TROYES. Cligès. Paris: Lettres Gotiques, 1994.

CHRÉTIEN DE TROYES. Erec et Enide. Paris: Lettres Gotiques, 1992.

CHRÉTIEN DE TROYES. Perceval ou le Conte du Graal. Paris: GF Flammarion, 1997.

\section{Estudos:}

BARTLETT, Robert. Trial by fire and water. The medieval judicial ordeal. Oxford: Oxford University Press, 2014.

DUBY, Georges. Damas do Século XII: A Lembrança das Ancestrais. São Paulo: Cia. das Letras, 1997.

DUBY, Georges. Women of the Twelfth Century: Eleanor of Aquitane and Six Others. Chicago: Chicago University Press, 1997.

DUBY, Georges. Women of the Twelfth Century: Eve and the Church. Chicago: Chicago University Press, 1998.

DUBY, G. \& PERROT. M. (org). História das Mulheres: a Idade Média. Lisboa: Afrontamento, 1990.

EVERGATES, Theodore, Aristocratic Women in the County of Champagne. In: EVERGATES, Theodore (ed.), Aristocratic Women in Medieval France. Philadelphia: University of Pennsylvania Press, 1999.

GINZBURG, Carlo. Fiction as Historical Evidence: a Dialogue in Paris, 1646. In: ROTH, Michael (org), Rediscovering History. Stanford: Stanford University Press, 1994, pp 378-388. 
LIVINGSTONE, Amy. Aristocratic Women in the Chartrain. In: EVERGATES, Theodore (ed.), Aristocratic Women in Medieval France. Philadelphia: University of Pennsylvania Press, 1999, pp. 44-73.

LoPRETE, Kimberly. Adela of Blois: Familial Alliances and Female Lordship. In: EVERGATES, Theodore (ed.), Aristocratic Women in Medieval France. Philadelphia: University of Pennsylvania Press, 1999, pp. 7-43.

MacNAMARA, J.; WEMPLE, S. Sanctity and power: the Dual Pursuit of medieval Women. In: BRIDENTHAL, R.; STUARD; WIESNER; (eds.) Becoming Visible. Women in European History. Boston: Houghton Mifflin, 1977, pp. 90-118.

PERNOUD, Régine. La Femme au Temps des Cathédrales. Paris: Plon, 1980.

PERNOUD, Régine. La Femme au temps de la Croisade. Paris: Stock, 1990.

POMATA, Gianna. Histoire des femmes, histoire du genre. Observations sur le Moyen Âge et l'époque moderne dans l'histoire des Femmes en Occident. In: DUBY, G.; PERROT. M. (eds.). Femmes et Histoire. Paris: Plon, 1992, pp. 25-38.

POMIAN, Krzysztof, "Histoire et Fiction” in Le Débat. 54, 1989, pp. 114-137.

POWER, Ei1een. Medieval Women. Cambridge: 1975.

SHAHAR, Shulamith, The Fourth Estate. London and New York: Routledge, 1996.

\footnotetext{
${ }^{1}$ Em relação à vida doméstica e familiar podemos destacar algumas obras de David Herlihy como "The Making of the Medieval Family: Symmetry, Structure, and Sentiment" in Journal of Family History. 8 (1983) 116-130; Medieval Households. Cambridge and London: Harvard University Press, 1985; "The Family and Religious Ideologies in Medieval Europe" in Journal of Family History. 12 (1987) 3-17. Especificamente sobre o casamento, a obra de Cristopher Brooke, The Medieval Idea of Marriage. Oxford: Clarendon, 1994. Sobre religiosidade feminina, as obras de Caroline Walker Bynum, Holy Feast and Holy Fast. Berkeley: University of California Press, 1987; Fragmentation and Redemption. New York: Zone Books, 1992. Também são importantes as diversas obras de Georges Duby - sobre as quais falaremos com mais detalhes ao longo deste trabalho - como O Cavaleiro, a Mulher e o Padre. Lisboa: D. Quixote, 1988; a trilogia Damas do Século XII e também a obra em conjunto com Michelle Perrot na coletânea História das Mulheres.

${ }^{2}$ Os argumentos de Duby não foram formulados em um único trabalho, mas aparecem em diversas obras suas, entre as quais podemos destacar: The Chivalrous Society. Berkeley, 1977; Medieval Marriage: Two Models from the Twelfth-Century. Baltimore, 1978; Histoire de la vie privée: De l'Europe féodal à la Renaissance. Paris: Éditions du Seuil, 1985; Le Chevalier, la femme et le pretre: la marriage dans la France féodal. Paris: Hachette, 1981; Male Moyen Age: de l'amour et autres essais. Paris: Champs Flammarion, 1990
} 